\title{
Biased thermohaline exchanges with the Arctic across the Iceland-Faroe Ridge in ocean climate models
}

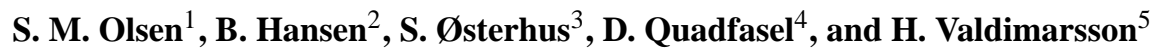 \\ ${ }^{1}$ Danish Meteorological Institute, Copenhagen, Denmark \\ ${ }^{2}$ Faroe Marine Research Institute, Tórshavn, Faroe Islands \\ ${ }^{3}$ Geophysical Institute, University of Bergen, Norway \\ ${ }^{4}$ Institute of Oceanography, Universität Hamburg, Germany \\ ${ }^{5}$ Marine Research Institute, Reykjavik, Iceland \\ Correspondence to: S. M. Olsen (smo@dmi.dk)
}

Received: 27 April 2015 - Published in Ocean Sci. Discuss.: 14 July 2015

Revised: 9 December 2015 - Accepted: 11 December 2015 - Published: 13 April 2016

\begin{abstract}
The northern limb of the Atlantic thermohaline circulation and its transport of heat and salt towards the Arctic strongly modulate the climate of the Northern Hemisphere. The presence of warm surface waters prevents ice formation in parts of the Arctic Mediterranean, and ocean heat is directly available for sea-ice melt, while salt transport may be critical for the stability of the exchanges. Through these mechanisms, ocean heat and salt transports play a disproportionally strong role in the climate system, and realistic simulation is a requisite for reliable climate projections. Across the Greenland-Scotland Ridge (GSR) this occurs in three well-defined branches where anomalies in the warm and saline Atlantic inflow across the shallow Iceland-Faroe Ridge (IFR) have been shown to be particularly difficult to simulate in global ocean models. This branch (IF-inflow) carries about $40 \%$ of the total ocean heat transport into the Arctic Mediterranean and is well constrained by observation during the last 2 decades but associated with significant interannual fluctuations. The inconsistency between model results and observational data is here explained by the inability of coarse-resolution models to simulate the overflow across the IFR (IF-overflow), which feeds back onto the simulated IFinflow. In effect, this is reduced in the model to reflect only the net exchange across the IFR. Observational evidence is presented for a substantial and persistent IF-overflow and mechanisms that qualitatively control its intensity. Through this, we explain the main discrepancies between observed and simulated exchange. Our findings rebuild confidence in modelled net exchange across the IFR, but reveal that com-
\end{abstract}

pensation of model deficiencies here through other exchange branches is not effective. This implies that simulated ocean heat transport to the Arctic is biased low by more than $10 \%$ and associated with a reduced level of variability, while the quality of the simulated salt transport becomes critically dependent on the link between IF-inflow and IF-overflow. These features likely affect sensitivity and stability of climate models to climate change and limit the predictive skill.

\section{Introduction}

The North Atlantic thermohaline circulation and its associated heat transport strongly affect the climate of the Northern Hemisphere (Rahmstorf and Ganopolski, 1999; Vellinga and Wood, 2002; Sutton and Hodson, 2005). Adequate simulation of the ocean heat transport towards the Arctic in global climate models is a requisite for realistic representation of the role of the ocean in the climate system (Rhines et al., 2008). In regions of the Arctic, modulation of the ocean heat content is a primary driver of sea-ice variability (e.g. Bitz et al., 2005; Årthun et al., 2012; Yashayaev and Seidov, 2015), with indirect impact on the continental climate of northern Europe (Yang and Christensen, 2012; Vihma, 2014). Realistic simulation of ocean heat anomalies is a prerequisite for understanding and predicting decadal climate variability (Latif and Keenlyside, 2011; Meehl et al., 2014; Guemas et al., 2014). From climate models, the stability and structure of the Atlantic Meridional Overturning Circulation (AMOC) depends 
in part on the representation of the ocean exchanges of heat and salt with the Arctic through warm, saline inflow and cold, dense outflows (e.g. Born et al., 2009; Danabasoglu et al., 2010; Köller et al., 2010; Wang et al., 2015).

East of Greenland, the warm surface manifestation of the thermohaline circulation consists of three separate inflows to the Nordic Seas across the Greenland-Scotland Ridge (GSR) (Hansen and Østerhus, 2000). This includes the Iceland branch in the Denmark Strait, the Iceland-Faroe inflow and the Faroe-Shetland Atlantic inflow. Ongoing programmes seek to monitor the volume, heat and salt transports associated with the inflows (EU FP7 NACLIM 20132017: www.naclim.eu), and time series exceeding or approaching 2 decades are becoming available for all branches. Coarse-resolution ocean general circulation models have previously been assessed and show good skill in simulating the variability of volume exchanges on seasonal to inter-annual timescales, but are limited to part of the exchange system (Olsen et al., 2008; Sandø et al., 2012). Here we focus on the inflow of Atlantic water across the IFR, which has proven to be challenging to simulate with confidence in models of different resolution and architecture. To assess and explain this, we apply the ocean component of the EC-Earth coupled climate model (Hazeleger et al., 2012) in a forced hindcast configuration allowing direct comparison with observations. EC-Earth is included in the Coupled Model Intercomparison Project Phase 5 (CMIP5) (Taylor et al., 2012). This choice of model also allows us to address directly uncertainties in poleward heat transport in climate projections linked to the representation of ocean exchanges (e.g. Koenigk and Brodeau, 2014).

The observational data set used for motivating this study, comparison and verification (see Sect. 2.1) includes recent revisions of transport estimates for the two main Atlantic inflow branches east of Iceland (Berx et al., 2013; Hansen et al., 2015) in addition to established series of the cold, dense return flow in the Faroe Bank Channel at the exit of the Faroe-Shetland Channel (Fig. 1a, Hansen and Østerhus, 2007; Olsen et al., 2008).

The Iceland-Faroe Ridge (IFR), of particular interest here, is a submarine ridge situated in a complex and dynamic oceanographic setting between Iceland and the Faroes. The deepest sill of $\sim 480 \mathrm{~m}$ (Fig. 1b) is close to the Faroes, whereas the Western Valley close to Iceland has a sill at about $400 \mathrm{~m}$. Warm and saline Atlantic water flows eastwards across the ridge (IF-inflow), carrying heat and salt from the Atlantic into the Norwegian Sea. According to measurements (Hansen et al., 2015), this is the Atlantic inflow branch across the GSR with the highest volume transport, $3.8 \mathrm{~Sv}$ on average, and a correspondingly high heat and salt transport.

Below the Atlantic water, there is an overflow of colder and less saline water from the Norwegian Sea back into the Atlantic (IF-overflow). Although not well constrained by observations, the IF-overflow is generally believed to approach
$1 \mathrm{~Sv}$ in volume transport (Hermann, 1967; Perkins et al., 1998; Beaird et al., 2013).

The most pronounced and long-lasting discrepancy between models and observations of the IF-inflow is for a period in 2002-2003, when both in situ observations and satellite altimetry show much weaker inflow than normal (Hansen et al., 2010). Model results typically do not indicate any significant weakening for the specific period (Sandø et al., 2012). This is also demonstrated to be the case for the hindcast simulation exploited here (Fig. 2a). This period started in late 2002 and lasted during most of 2003. In the following, we denote it the "2003-event".

We suggest that both the observations and model results do reflect the variations of the exchanges across the IFR realistically, but that they represent different aspects of the exchanges and need further interpretation. In nature, there are two flows crossing the IFR, and the net poleward volume transport across the ridge is the intense IF-inflow minus the weaker IF-overflow. In global models, the resolution prevents any realistic simulation of IF-overflow, most clearly demonstrated in coarse-resolution models featuring no IF-overflow. In these models, the transport across the IFR consists of Atlantic inflow, solely.

Our hypothesis is that the volume transport across the IFR simulated by ocean climate models may be a fairly realistic representation of the actual net flow, but that the intensity should be interpreted as IF-inflow minus IF-overflow, rather than pure IF-inflow. Consequently, the relative steadiness of the net exchange modelled throughout the 2003-event, the IF-overflow in nature, must also have been abnormally weak during the observed 2003 inflow event. The motivation to suggest this interpretation also stems from skilful simulation of the characteristics of other exchange systems. Only an interpretation in terms of net transport will not compromise the mass balance requirement of the exchanges.

A fully satisfactory verification of this suggestion would require simultaneous time series of inflow as well as overflow transport, based on observations, but there are no observationally based time series of IF-overflow volume transport. There are, however, observations that, qualitatively, may indicate the strength of the IF-overflow. They do not allow detailed comparisons, but may illuminate conditions during extreme periods. This is why much of the treatment will be focused on the 2003-event, which is by far the most extreme discrepancy between observed and simulated IF-inflow.

If our hypothesis is correct, it may not have large implications for the volume (mass) budget of the Arctic Mediterranean, since the simulated net exchange might still be correct. The heat budget would, however, be affected since each $\mathrm{m}^{3}$ of IF-inflow carries much more heat than $1 \mathrm{~m}^{3}$ of IFoverflow. The IF-overflow is also much less saline than the IF-inflow, which has implications for the salt (freshwater) budget and which has the potential to feed back on the intensity and stability of the simulated exchanges and thermoha- 

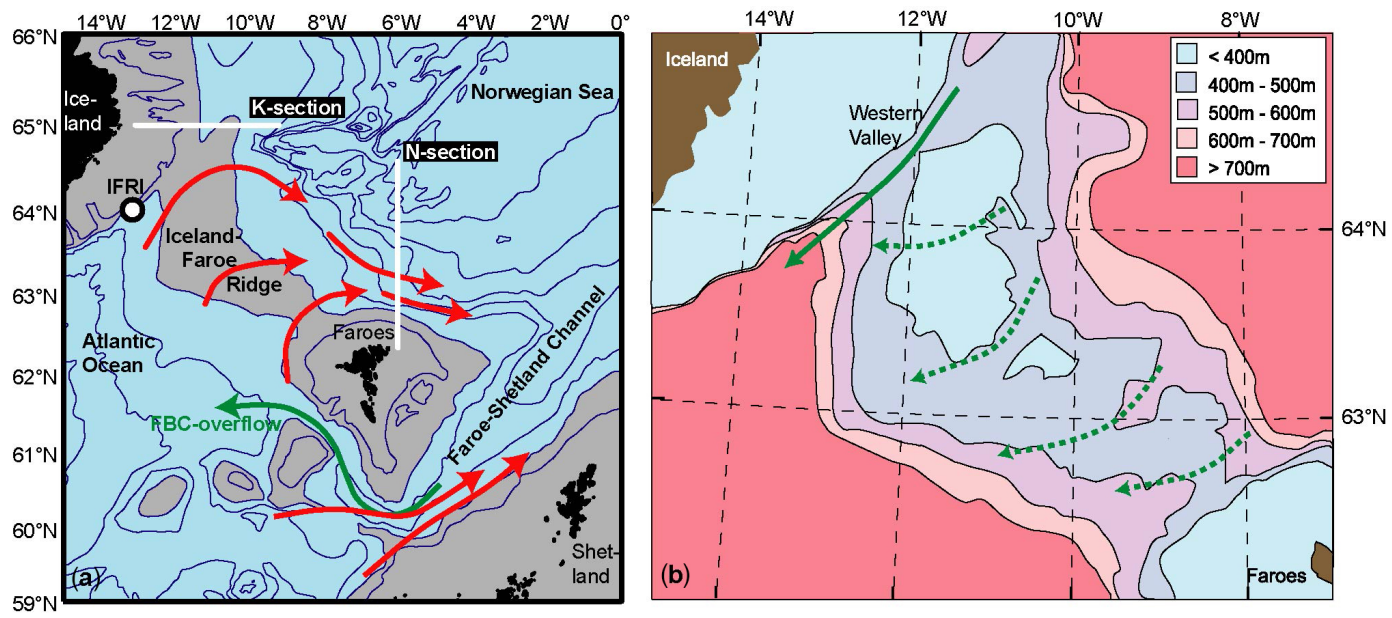

Figure 1. Map of the region (grey areas shallower than $500 \mathrm{~m}$ ) with red arrows schematically showing the flow of Atlantic water in the two main inflow branches and the green arrow the overflow through the Faroe Bank Channel (FBC). White lines indicate two standard sections. The circle indicates the location of ADCP mooring IFRI (a). Detailed topography of the IFR with green arrows indicating persistent (continuous) and intermittent (dashed) overflow according to Hansen and Østerhus (2000) (b).

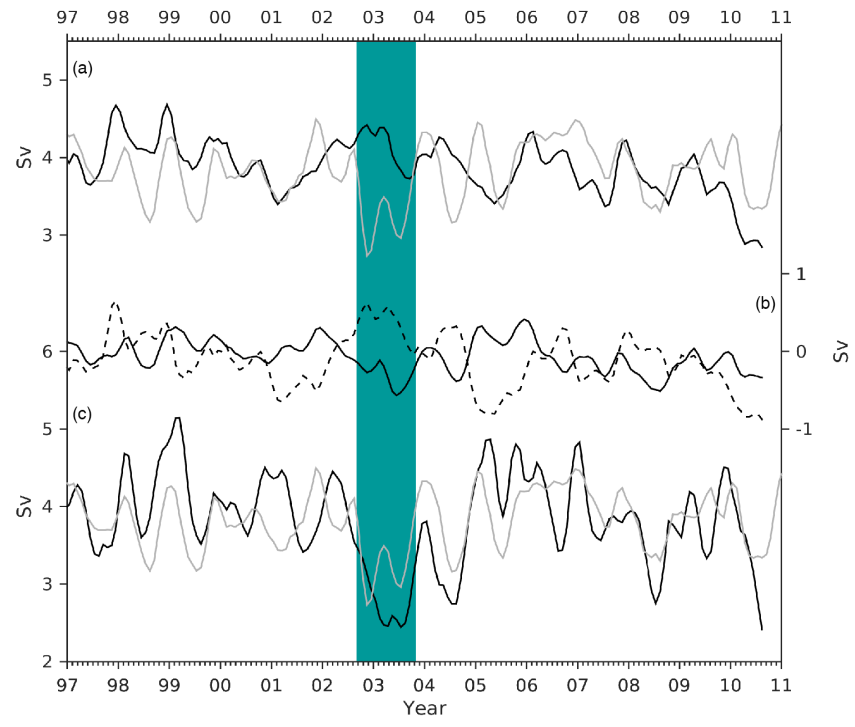

Figure 2. Three-month running mean time series of observed (grey; see Sect. 4.2) and modelled (black) IF-inflow (a). Anomalies (running mean) in modelled components on the Icelandic side (dashed) and Faroe side (solid) are shown in (b). Modelled transport of water denser than $27.8 \mathrm{~kg} \times \mathrm{m}^{-3}$ across a model section north from the Faroes close to the observational N-section (Fig. 1a) is shown (black) together with observed IF-inflow (grey) in (c). The shaded bar indicates the 2003-event.

line circulation, as suggested already by Stommel (1961) and verified in numerous model studies (e.g. Latif et al., 2000).

In this paper, we first present conditions and model results characterizing the 2003-event. We then present observational results that may be used to estimate transport variations in both the IF-inflow and IF-overflow. Based on these observa- tional results, we discuss the extent to which the discrepancy between observations and global climate models can be reconciled and what the consequences are for climate simulations of the oceanic heat transport towards the Arctic.

\section{Model results}

\subsection{Configuration and experiment}

To demonstrate the general skill of global CMIP5-type ocean models in simulating the ocean exchanges with the Arctic and to facilitate direct comparison with observations, an ocean hindcast simulation has been conducted using the EC-Earth climate model configured in a forced hindcast mode. The applied version (V2.2) of EC-Earth (Hazeleger al., 2012) is a fully coupled atmosphere ocean general circulation model (AOGCM), which builds on the Nucleus for European Modeling of the Ocean (NEMO) system coupled to the LIM2 sea-ice module.

The ocean configuration of NEMO has a resolution of $1^{\circ} \times 1^{\circ}$ with a meridional refinement to $1 / 3^{\circ}$ at the Equator, referred to as the ORCA1 grid. Here, the singularity at the North Pole is avoided by use of a tri-polar grid with poles over land (Siberia, Canada, Antarctica). Using 42 vertical $z$-layers, vertical ocean resolution increases from $10 \mathrm{~m}$ at the surface to $300 \mathrm{~m}$ at depth and reaches down to $5500 \mathrm{~m}$. The large-scale ocean circulation in the coupled system is in good agreement with the present views (see Sterl et al., 2012, and references herein) and general characteristics of the Arctic-subarctic ice-ocean exchange system have been convincingly assessed in Koenigk and Brodeau (2014).

The uncoupled simulation for the period 1948-2011 is forced by 6-hourly atmospheric NCEP reanalysis data 
(Kalnay et al., 1996). Runoff is prescribed from climatology and we make use of sea-surface salinity restoring (app. 180 days for a $10 \mathrm{~m}$ mixed layer). Using an annually permuted NCEP forcing sequence (see Olsen and Schmith, 2007), an independent 300-year spin-up has been performed, and the quasi-equilibrium climate state of the ocean simulations has shown a modest drift in water mass properties relative to climatology.

\subsection{Exchanges across the GSR}

Time series of volume transports across the GSR have been calculated in discrete density bins and integrated across a set of closed model sections representing approximately the branches of the ocean exchange system equipped with moored oceanographic transport monitoring systems. Monthly mean net inflows or outflows are obtained using a density criterion to separate light and dense branches (e.g. Olsen and Schmith, 2007). For the IFR and Faroe-Shetland Channel, inflow is defined by the net transport lighter than $\sigma=27.8 \mathrm{~kg} \times \mathrm{m}^{-3}$ in agreement with observational procedures. In the model, the coarse grid resolution does not allow resolution of the topographic detail of the ridge, which possibly explains in part why the overflow here is effectively zero $(<0.1 \mathrm{~Sv})$.

The modelled time series of the IF-inflow has a mean value of 3.89 Sv (1997-2011) nearly identical to the observed inflow. The modelled time series is compared with observations in Fig. 2a, illustrating the discrepancy during the 2003-event. Evidently, the correlation between observed and modelled IF-inflow is weak $(r=0.21)$, and contrasts with the high degree of explained variance found for the FaroeShetland inflow $(r=0.80)$ and the Faroe Bank Channel overflow $(r=0.81)$ using de-trended monthly data filtered with a 3-month running mean. The IF-inflow in the model may be decomposed into a transport on the north-western (Icelandic) side of the IFR and a transport on the south-eastern (Faroe) side with average contributions of comparable magnitude. Anomalies in these are found to be significantly negatively correlated with $r=-0.44$ for the observational period 19972011 ( $r=-0.71$ for the full simulation period, Fig. 2b), in turn justifying a decomposition of the exchange. Also noteworthy, modelled transport on the Faroe part of the ridge is found to correlate significantly better with the observed IFinflow in section $\mathrm{N}(r=0.59)$, but with a regression coefficient of only 0.53 . This may be indicative of a qualitatively realistic model response but with reduced sensitivity or a systematic underrepresentation of an important feedback.

\subsection{Surface forcing during the 2003-event}

Compared to average conditions, the winter of 2002-2003 was characterized by an intensified meridional component of the wind stress over the northern North Atlantic (Fig. 3). Relaxation of the positive zonal wind stress off the British Isles opened up for a coherent band with a positive anomalous meridional wind-stress component stretching across the subpolar Atlantic into the Norwegian Sea. The monthly mean North Atlantic Oscillation (Hurrell, 1996) index was positive in January through to March 2003, but did not reflect an extreme situation. Across the entire IFR, the magnitude of the positive meridional wind-stress anomaly (Fig. 3b) compared with or exceeded the climatic winter mean for the period 1996-2010. Within the Nordic Seas, the region off Greenland with negative (southward) wind stress was more coastally confined and had a reduced strength over the path of the southward flowing East Greenland Current. In the western Irminger Sea south of the Denmark Strait, negative anomalies in zonal wind stress express an intensification of the prevailing winds with a strong along-coast component.

A general increase in sea level was observed for the Nordic Seas and neighbouring parts of the sub-polar region in response to the anomalous wind regime (Fig. 4a). The uniform pattern of change north of the GSR cannot on this timescale be explained by steric effects and must predominantly describe a change in volume. This derives from transient (days to a week) imbalances in the two-way ocean exchanges across the GSR whereby sea-level, wind and thermohaline driven exchanges mutually adjust through a set of feedbacks necessarily including barotropic forcing (Lake and Lundberg, 2006; Olsen et al., 2008; Hansen et al., 2010).

Simulated basin-scale sea-level responses to the anomalous atmospheric conditions (Fig. 4) compare well with the observed anomaly in the Nordic Seas for both the general spatial pattern and the magnitude of changes (Fig. 4a, b). Important and partly expected differences considering the viscous nature of the coarse model product include a moderate underestimation of the absolute magnitude of anomalies. In the region north-east of the IFR, observed sea-level anomalies show local details, which highlight the dynamic response downstream of the IF-inflow.

According to observations, the strength of the IF-inflow responded negatively to these conditions (Hansen et al., 2010), as also seen in the sea-level anomalies. The significant weakening here is opposite to the expected direct response from wind-stress forcing (Fig. 3b, Hansen et al., 2010). Indeed, the model also shows no coherent intensification in simulated upper-ocean currents in response to the intensified meridional wind stress across the IFR (Fig. 5b), and correlations between monthly averages of inflow and wind stress are found to be very weak on monthly timescales $(r<0.1$, Fig. 3c), consistent with other studies (Richter et al., 2012). Only a weak tendency to northward redirection of the IFinflow (Iceland component) is modelled within the Norwegian Sea (Figs. 2b, 5b).

In Hansen et al. (2010), the weakening of the IF-inflow during the 2003-event has been characterized as a result of the reduced sea-level forcing across the IFR observed in altimetry during the winter months 2002-2003 (Fig. 4c). A number of processes may explain this link, and we repre- 

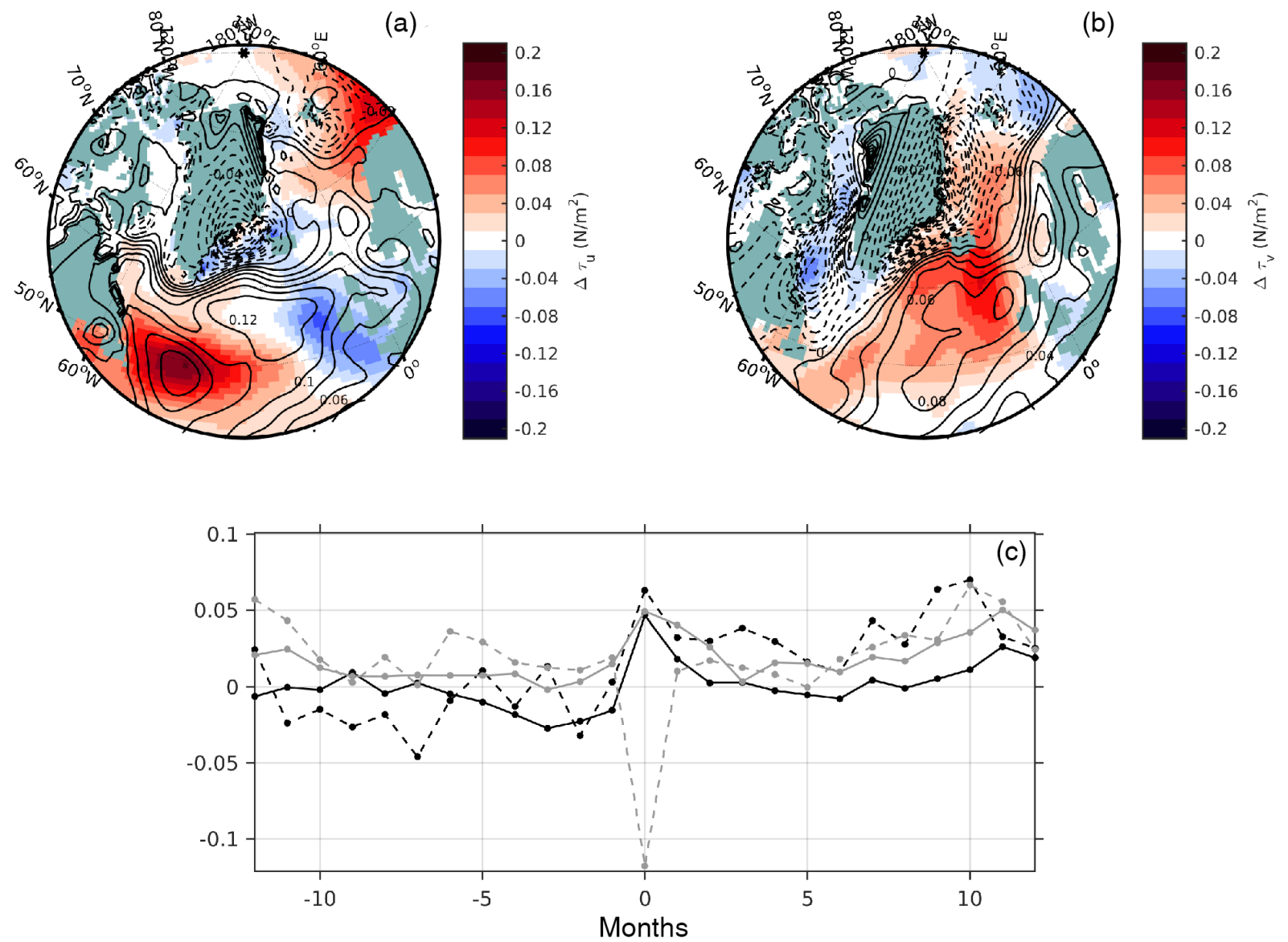

Figure 3. Winter (JFM) 2003 zonal (a) and meridional (b) wind-stress anomalies, respectively. Contours show the climatic winter average for the period 1996-2010. The panels show atmospheric NCEP reanalysis data (Kalnay et al., 1996) on the grid mask of the global ocean model. Lagged correlations in (c) are between modelled monthly mean IF-inflow anomalies for the Iceland (dashed) and Faroe (solid) components, respectively (Fig. 2). Results are calculated for zonal (black) and meridional (grey) wind-stress anomalies, respectively, on the ridge (approx. $\left.64^{\circ} \mathrm{N}, 11^{\circ} \mathrm{W}\right)$.

sent this forcing in the model as the difference between sea-surface height on four grid points on either side of the IFR. This difference is compared against observations of sealevel anomalies in Fig. 4c. In contrast to the intensity of the IF-inflow, the model system does realistically simulate the fluctuating sea-level forcing during the 2003-event. In the model, however, the event was modest (app. $4 \mathrm{~cm}$ ) relative to the pressure gradient forcing deriving from the average sea-surface height difference of $26 \mathrm{~cm}$ (1997-2011, Fig. 4c). Moreover, the model exchange is seen not to be directly controlled by this forcing term. It is difficult to verify the mean level of the simulated pressure gradient across the ridge but, if unrealistic, it would help to explain the limited model sensitivity for this exchange branch.

\subsection{Simulated interface changes in the Nordic Seas}

If indeed the reduced variability in modelled IF-inflow during the 2003-event is linked to the limited representation of overflow across the sill as suggested in the Introduction, changes within the Nordic Seas should reflect conditions favouring a decreased intensity of the IF-overflow during this period, though unresolved. In fact, this is what we find by studying the baroclinic response in the Nordic Seas using the interface between upper water masses and dense, cold water potentially contributing to overflows. From observations, this interface is typically described by the depth of the $27.8 \mathrm{~kg} \times \mathrm{m}^{-3}$ isopycnal. The representation of this interface is fairly realistic, shoaling from approximately $500 \mathrm{~m}$ northeast of the IFR to $100 \mathrm{~m}$ in the central part of the cyclonic gyre of the Nordic Seas (Fig. 5c).

The anomalous conditions in winter 2002-2003 (Fig. 5d) are dominated by a further shoaling of the interface in the Greenland Sea and deepening in the Lofoten Basin but, more importantly, an isolated deepening of the interface $30-50 \mathrm{~m}$ north-east of the IFR. Simple two-layer models of overflow intensity (Whitehead, 1998) suggest that, depending on the configuration, this could be sufficient to explain large vari- 

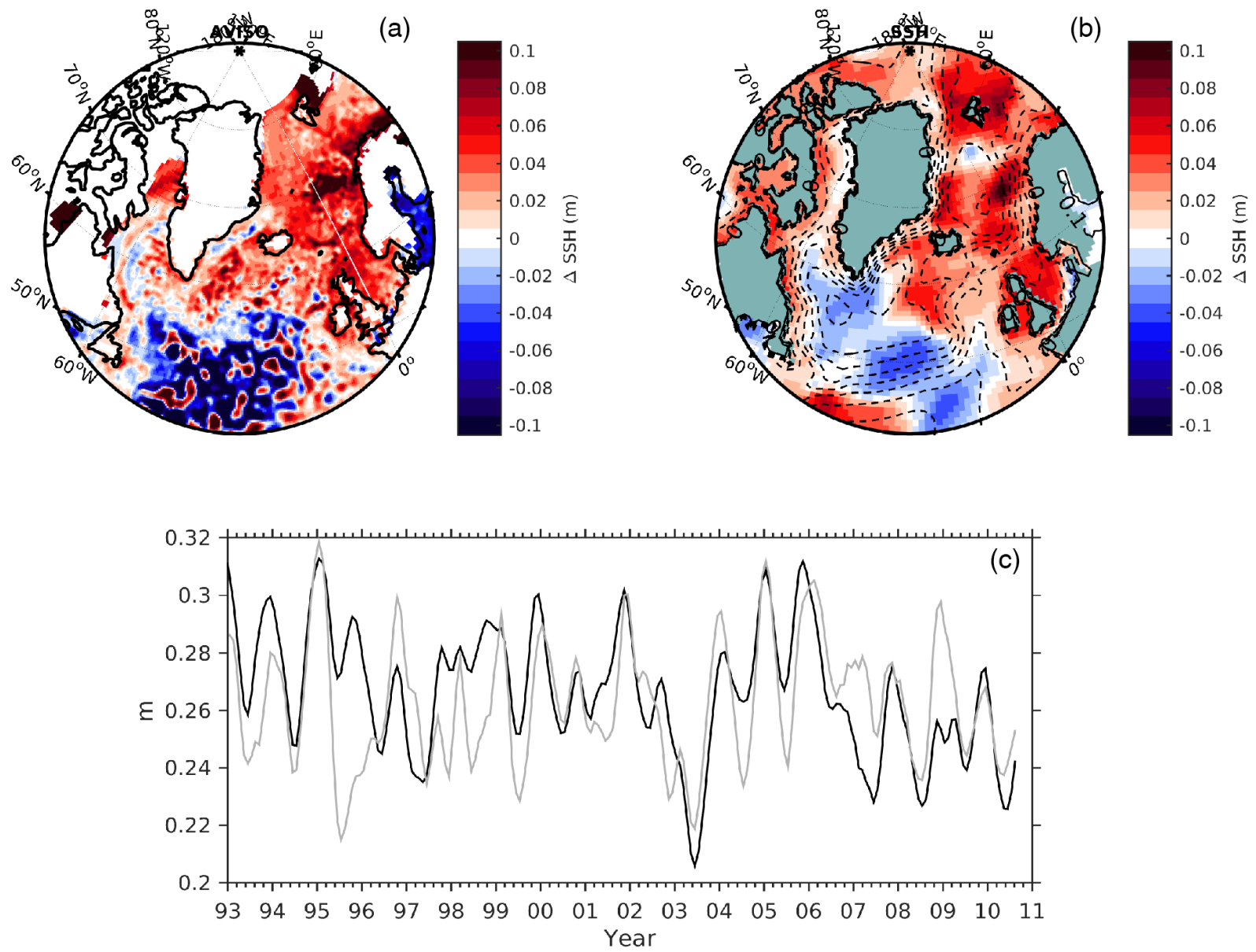

Figure 4. Observed AVISO (http://www.aviso.oceanobs.com/duacs/) mean sea-level anomaly (MSLA) for JFM 2003 (a) compared with modelled (b) sea-surface height anomaly for JFM 2003 relative to the climatic winter average for the period 1996-2010. Contours in (b) represent closed streamlines of the vertically averaged model circulation. In (c) we compare time series of sea-surface height difference across the IFR between model (black) and observations (grey). The observed sea-surface height difference is based on an average of AVISO mean sea-level anomalies for four model grid points west of the IFR minus four points east of the IFR, approximately at the $2500 \mathrm{~m}$ isobaths. Observations have been artificially offset to fit the model mean gradient.

ations in IF-overflow intensity. In the model, the interface deepening results in a strong decline in the transport of dense water through the model representation of section $\mathrm{N}$ north of the Faroes (Fig. 2). This flow is found to correlate surprisingly well with the observed weakening of the IF-inflow.

\section{Observational material}

To describe the water mass characteristics east of the IFR, we use observations from two standard sections. The "Ksection", operated by the Marine Research Institute in Iceland since 1974, has six standard stations extending from station $\mathrm{K} 1$ located at $50 \mathrm{~m}$ depth on the shelf east of Iceland at $65^{\circ} \mathrm{N}, 13.5^{\circ} \mathrm{W}$, along the $65^{\circ} \mathrm{N}$ latitude, to station $\mathrm{K} 6$, at $65^{\circ} \mathrm{N}, 9^{\circ} \mathrm{W}$, with a bottom depth of $1200 \mathrm{~m}$.

The "N-section", operated by the Faroe Marine Research Institute since 1988, has 14 standard stations, extending from station N01 located at $80 \mathrm{~m}$ depth on the shelf north-east of the Faroes at $62.167^{\circ} \mathrm{N}, 6.083^{\circ} \mathrm{W}$, along the $6.083^{\circ} \mathrm{W}$ meridian, to station $\mathrm{N} 14$ at $64.5^{\circ} \mathrm{N}, 6^{\circ} \mathrm{W}$, with a bottom depth of $3300 \mathrm{~m}$. Both sections have typically been visited four times a year.

On the N-section, data on the velocity field have been available since 1997 from a regular array of ADCPs (acoustic Doppler current profilers). Details of the observations and their processing may be found in Hansen et al. $(2003,2010$, 2015).

We also use data from an ADCP moored at site "IFRI" (Fig. 1a) at $601 \mathrm{~m}$ bottom depth on the Icelandic slope west of the IFR at position $63^{\circ} 57.910^{\prime} \mathrm{N}, 13^{\circ} 31.070^{\prime} \mathrm{W}$ from 1 September 2005 to 4 October 2007. The ADCP was an RDI Long Ranger mounted inside a trawl-protected frame with $10 \mathrm{~m}$ bin length, with the first bin centred $19 \mathrm{~m}$ above the bottom and a 20 min sampling interval. 

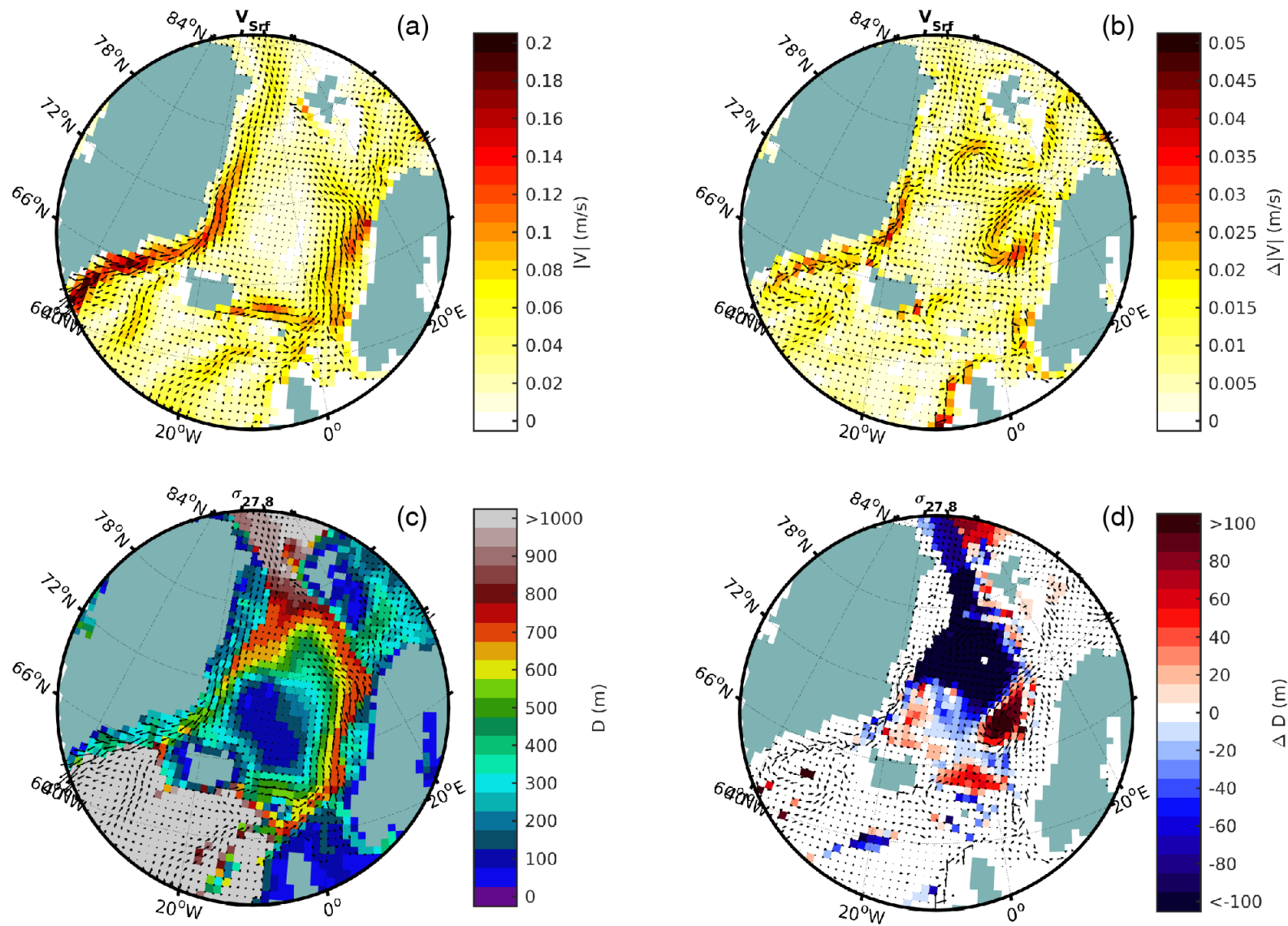

Figure 5. Modelled average winter (JFM) circulation at approx. $100 \mathrm{~m}$ depth (a) and average depth of the $27.8 \mathrm{~kg} \times \mathrm{m}^{-3}$ isopycnal (c) in the Nordic Seas for the period 1996-2010. The anomalous circulation pattern (b) and depth changes of the $27.8 \mathrm{~kg} \times \mathrm{m}^{-3}$ isopycnal (d) describe the response to the JFM 2003 conditions relative to the average. Vectors in (c) and (d) correspond to average (a) and anomalous (b) circulation patterns, respectively.

To map sea-level variations, we have obtained MSLA data from AVISO (see Fig. 4a). The data are on a rectangular grid with approximately $18 \mathrm{~km}$ resolution and are sampled once a week. By interpolation between neighbouring altimetry grid points, we have generated time series of weekly MSLA values for each standard station in the two standard sections.

\section{Observational results}

\subsection{Hydrography}

Average distributions of potential temperature, salinity, and potential density $\left(\sigma_{\theta}\right)$ along the two standard sections are shown in Fig. 6. For comparability, we have used the same averaging period and only included cruises with complete section coverage, except for station K6, which has often been skipped.

On the K-section, we only find waters of Arctic origin with salinity $\leq 34.9$. On the $\mathrm{N}$-section, these water masses are at depth and in the northern part of the section. The upper lay- ers in the southern part of the $\mathrm{N}$-section are dominated by high-salinity water that has crossed the IFR. These waters are denoted "Atlantic". The colder and less saline water masses below the Atlantic water will here be termed "dense".

The $\sigma_{\theta}=27.8 \mathrm{~kg} \times \mathrm{m}^{-3}$ isopycnal is often used to distinguish between overflow water and upper water masses (Dickson and Brown, 1994). This isopycnal is enhanced in Fig. 6 and will in the following be referred to as the "interface". Over the outer parts, the two sections have similar hydrographic properties, and the interface is located at depths from 100 to $200 \mathrm{~m}$, on average. As we approach the shallower parts of the two sections, a clear difference is seen. On the K-section, the average interface remains shallower than $200 \mathrm{~m}$, but on the $\mathrm{N}$-section downstream of the Atlantic inflow across the IFR, it descends to $\sim 500 \mathrm{~m}$ on approaching the slope north of the Faroes.

As mentioned in Sect. 2.3, changes in sea level will often lead to changes in the depths of the isopycnals below by baroclinic adjustment. To check this for the K-section, we have correlated the depth of the interface, denoted $D_{I}$, for each standard station as determined during each cruise with 

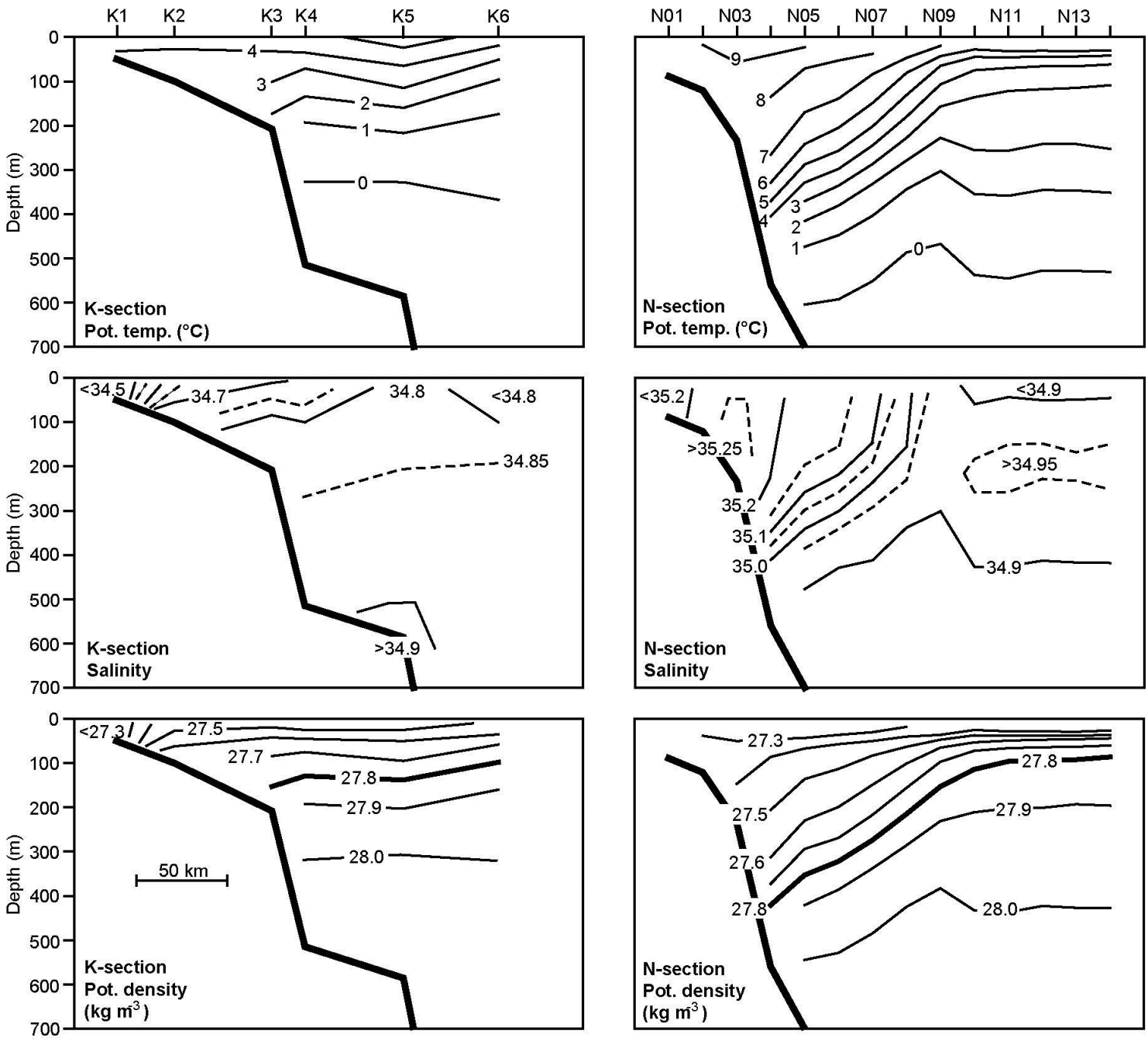

Figure 6. Average hydrographic properties in the two sections 1996-2012, based on 59 cruises at the K-section (only 46 at K6) and 51 cruises at the $\mathrm{N}$-section. The horizontal scale is equal for all the panels and is shown in the bottom left panel.

the MSLA value at the station during the same week as the cruise, lagged by a variable number of weeks. The highest correlations are generally found when $D_{I}$ is lagged behind the MSLA values (Fig. 7 and Table 1). For the two innermost, sufficiently deep stations (K3 and K4), the highest correlations are found for a lag of about 2 months, in which case the correlation explains about $50 \%$ of the variance in $D_{I}\left(r^{2} \approx 0.5\right)$.

Since there is considerable autocorrelation in the MSLA data, the lag could be a statistical artefact. The autocorrelation function for the MSLA values is, however, relatively narrow, and the cross-correlation functions go rapidly to zero for negative lags, i.e. when $D_{I}$ leads the MSLA values (Fig. 7). This indicates that the lags are real, which means that the depth at which the interface intersects the Icelandic slope at station $\mathrm{K} 4$ (denoted $D_{\mathrm{K} 4}$ ) is fairly well correlated with sea level on the section, but lagged by a period that is a couple of months on average, although variable.
We expect the depth of the interface over the slope east of Iceland to be an important forcing factor for IF-overflow and seek a continuous representation of this depth. This could be based on the regression analysis for station K4, but a temporal trend in the MSLA values for the station was not reflected in the observed interface depth. We therefore used a multiple regression analysis with time as the second independent variable. In this way, a continuous time series of the interface depth at station $\mathrm{K} 4, D_{\mathrm{K} 4}(t)$, was generated, which explained $52 \%$ of the variance in the observed interface depth. Subtracting this series from the sill depth of the Western Valley $(400 \mathrm{~m})$, we get a time series, $h_{\mathrm{u}}(t)=400 \mathrm{~m}-D_{\mathrm{K} 4}(t)$, termed the reconstructed upstream interface height, which in the ideal case ought to be a main controlling factor for overflow across the northern part of the IFR. 
Table 1. Characteristics of the interface depth $\left(D_{I}\right)$ at each of the deep standard stations on the K-section and its correlation coefficient with the MSLA value at the station.

\begin{tabular}{lrrrr}
\hline & K3 & K4 & K5 & K6 \\
\hline Number of values: & 59 & 69 & 67 & 45 \\
Average $D_{I}(\mathrm{~m}):$ & 124 & 122 & 136 & 96 \\
Standard deviation $D_{I}(\mathrm{~m}):$ & 47 & 46 & 45 & 37 \\
Correlation coefficient for zero lag: & 0.38 & 0.46 & 0.63 & 0.54 \\
Maximum lagged correlation coefficient: & 0.72 & 0.70 & 0.63 & 0.71 \\
Lag giving maximum correlation coeff. (weeks): & 8 & 10 & 0 & 3 \\
\hline
\end{tabular}

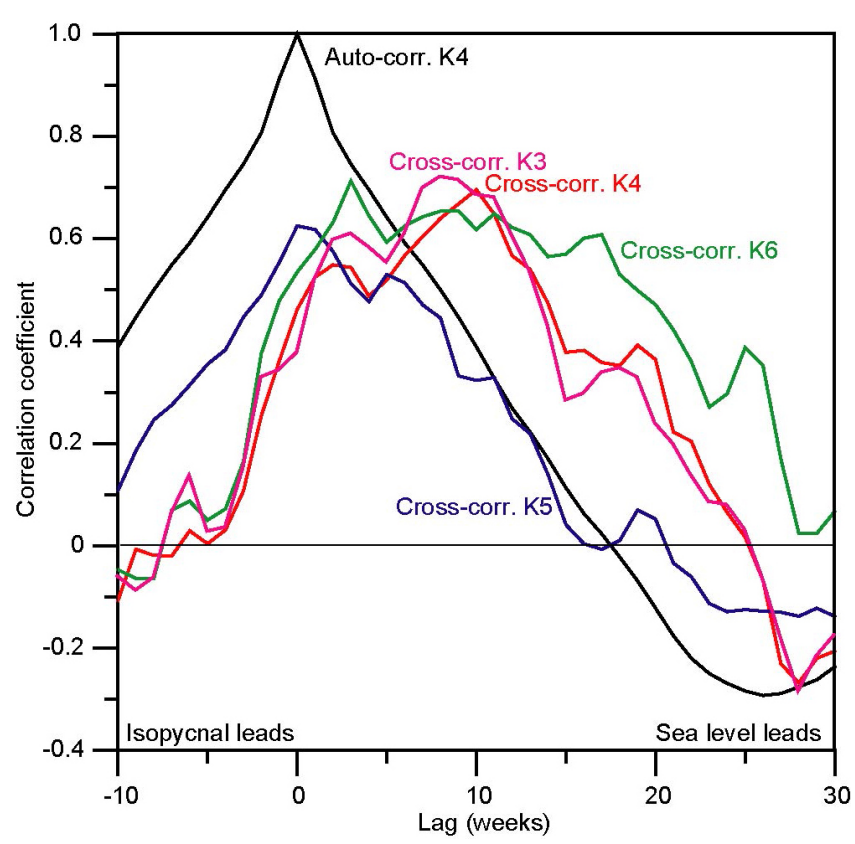

Figure 7. Autocorrelation of the MSLA value at station K4 (black) and lagged cross-correlation between the depth of the interface $\left(D_{I}\right)$ and associated MSLA value for stations K3 (purple), K4 (red), K5 (blue), and K6 (green).

\subsection{The flow through the N-section}

When plans for monitoring the IF-inflow were discussed in the early 1990s, the logistical problems associated with in situ moorings on the wide, topographically complex, and heavily fished IFR led to the alternative choice of the Nsection for the monitoring array. As seen in Fig. 6, the warm and saline Atlantic water is typically confined to the southern half of this section in a well-defined boundary current. Although its extent may vary, a large number of CTD cruises confirm that the Atlantic water remains within the $\mathrm{N}$-section.

Originally, observational estimates of the volume transport through this section were based solely on in situ observations (Hansen et al., 2003), but comparisons demonstrated high correlations of these estimates with sea-level data obtained by altimetry (Hansen et al., 2010) - notably during the 2003- event. Recently this has led to a recalculation of the transport by combining in situ and altimetry data. This has generated a new time series spanning the whole altimetry period since 1 January 1993. This series is without data gaps, although the quality will be best with high coverage of in situ instrumentation after 1997 (Hansen et al., 2015). We denote this transport time series IF-inflow, and this is the observational series shown in Fig. 2.

The ADCP array on the $\mathrm{N}$-section was not designed to monitor the flow of dense water, located below the Atlantic water, and we do not have good observational estimates of the volume transport of dense water through the section. One of the ADCP sites on the N-section, site $\mathrm{NB}$ at $62.92^{\circ} \mathrm{N}$, $6.083^{\circ} \mathrm{W}$, has, however, had an ADCP deployed deeper than $700 \mathrm{~m}$ since 1998 . The deepest velocity measured by this ADCP, at a depth of $\sim 675 \mathrm{~m}$, represents the velocity of the dense water flow due north of the Faroe slope and is likely to be fairly well correlated with the volume transport of dense water. This velocity co-varies relatively well with the IFinflow $(r=0.55)$. We note especially that this deep velocity series is negative or low during the 2003-event and so consistent with the simulated dense water transport (Fig. 2c).

\subsection{Overflow at the Western Valley}

The average velocity profile from the 2-year deployment at $600 \mathrm{~m}$ depth at site IFRI (Fig. 1a) due west of the IFR indicates a strong $\left(\sim 50 \mathrm{~cm} \times \mathrm{cm}^{-1}\right)$ current close to the bottom, directed along the bottom topography away from the IFR (towards $236^{\circ}$ ) with the core located about $60 \mathrm{~m}$ above the bottom (Fig. 8a).

Although the core velocity varied, it never fell below $30 \mathrm{~cm} \times \mathrm{s}^{-1}$ on weekly average, throughout the deployment (Fig. 8b). The bottom temperature was negatively related to core velocity (correlation coefficient -0.43 for 107 weekly averages), but did not rise above $5.5^{\circ} \mathrm{C}$. This flow is similar to the observations reported by Perkins et al. (1998) from a mooring located just a few hundred metres away from the IFRI site in slightly deeper water $(639 \mathrm{~m})$, confirming the persistence of this flow. Any source other than overflow for such a strong deep flow would be difficult to imagine. Beaird et al. (2013) have shown that any overflow from the Faroe Bank Channel or from the southern part of the IFR would 

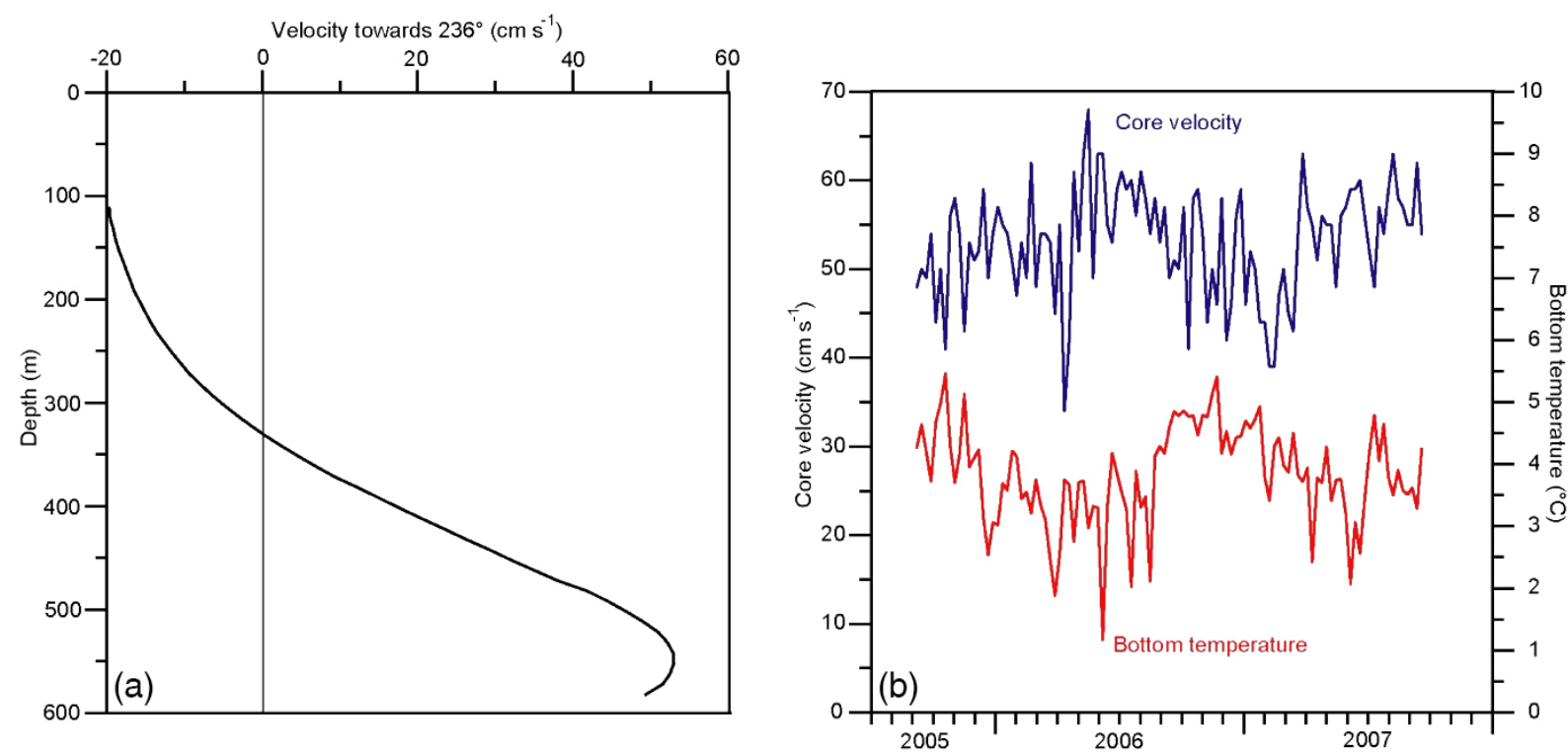

Figure 8. Results from the ADCP at site IFRI (Fig. 1a). Vectorially averaged velocity profile towards $236^{\circ}$ (a). Weekly averaged velocity towards $236^{\circ}$ for bin 4 , approximately $60 \mathrm{~m}$ above the bottom (blue) and weekly averaged bottom temperature (red) (b).

have descended below $1000 \mathrm{~m}$ at the IFRI location. Though the detailed pathway may not be clear, it seems evident that this flow derives from overflow across the northern part of the IFR, and the high speed of the flow must derive from potential energy converted to kinetic energy by deepening isopycnals. Ignoring friction, the interface deepening $\Delta \mathrm{H}$ necessary for accelerating a quiescent water parcel up to a speed of $\mathrm{U}=0.5 \mathrm{~m} \times \mathrm{s}^{-1}$ follows from Bernoulli's equation, $\Delta \mathrm{H}=\mathrm{U}^{2} / 2 g^{\prime} \approx 40 \mathrm{~m}$, where we have assumed a two-layer system with a density difference between the overflow and upper water layers of $0.3 \mathrm{~kg} \times \mathrm{m}^{-3}\left(27.8-27.5 \mathrm{~kg} \times \mathrm{m}^{-3}\right)$.

This calculation indicates that the interface at station K4 upstream of the IFR is more than sufficiently high above the sill of the IFR to generate an overflow current of the speed observed, and Fig. 9 compares the observed core velocity at IFRI with the reconstructed interface height, $h_{\mathrm{u}}(t)$, defined in Sect. 4.1. Interface heights based on observed $D_{\mathrm{K} 4}$ values from six cruises in the period are also shown.

On short timescales, there is no similarity between $h_{\mathrm{u}}(t)$ and the core velocity at IFRI. For weekly averaged data (107 values), the correlation coefficient was 0.00 . After passing the sills, overflows are notoriously affected by highfrequency meso-scale processes (Swaters, 1991; Voet and Quadfasel, 2010; Guo et al., 2014). Thus, a lack of shortterm correlation was to be expected. When averaged over 4 weeks (26 values), the correlation coefficient increased to 0.38 and, for 12-week averages (8 values), it increased to 0.72 , but there are few degrees of freedom, and most of this could be explained by similar seasonality in both series. Figure 9 also includes the volume transport of IF-inflow for the same period (green curve). This series remains above average

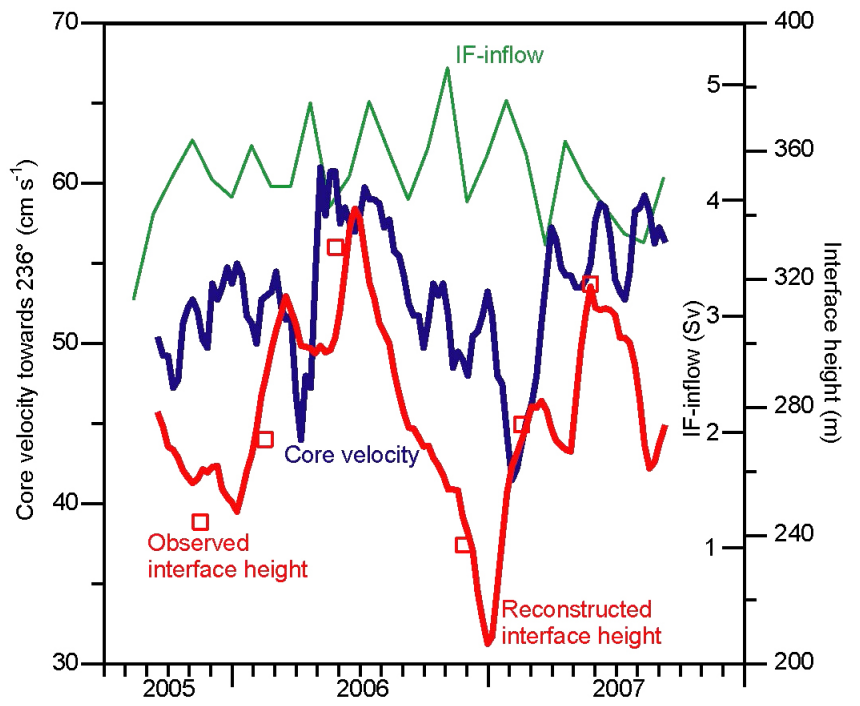

Figure 9. Comparison of core velocity (towards $236^{\circ}$ ) at site IFRI and interface height at station $\mathrm{K} 4$ above the sill level of the IFR close to Iceland $\left(h_{\mathrm{u}}\right)$ as well as IF-inflow. Continuous lines represent 4-weekly averaged core velocity (blue), reconstructed interface height (red), and IF-inflow (green). Red rectangles indicate interface height based on the observed interface depth at K4.

(3.8 Sv) during most of the period and shows no co-variation with the other two series. 


\section{Discussion and implications}

\subsection{The discrepancy between simulated and observed IF-inflow}

The model used in this study has demonstrated good skill in simulating observed variability of the Faroe-Shetland Channel (FSC) Atlantic inflow as well as the inflow west of Iceland (detailed in Sect. 2). Yet, for the IF-inflow, the correlation coefficient is only 0.21 , even though this is by far the strongest branch, with average volume transport $3.8 \mathrm{~Sv}$, compared to $2.7 \mathrm{~Sv}$ for the flow through the FSC (Berx et al., 2013) $(r=0.80)$ and $0.9 \mathrm{~Sv}$ west of Iceland $(r=0.42)$ (Jónsson and Valdimarsson, 2012).

In the Introduction, we suggested that the explanation for this discrepancy lies in the inability of any coarse-resolution model to simulate the IF-overflow adequately, so that the simulated IF-inflow in effect is the net exchange across the IFR: inflow minus overflow. Validation of the model in this region then requires comparison between simulated and true, observed, net inflow across the IFR, which again requires evaluation of the IF-overflow.

Unfortunately, our knowledge of the IF-overflow and its variations is very limited. Classical studies (Hermann, 1967; Meincke, 1983) demonstrated overflow to occur widely distributed along the width of the IFR, but mainly intermittently (Fig. 1b). In the region of the Western Valley, the direct current measurements by Perkins et al. (1998) and those illustrated in Fig. 8 do, however, indicate a persistent overflow, although variable. In their glider study, Beaird et al. (2013) found higher variability, but gliders are not ideal for studying a narrow high-velocity bottom current. From Figs. 6 and 9a it is also clear that the interface at the K-section - the upstream top of overflow water - is typically far above the sill level of the Western Valley. This would be expected to generate an overflow hugging the Icelandic slope and passing through the Western Valley.

To get an impression of the overflow to be expected under these conditions, we considered the simple twolayer model illustrated in Fig. 10a. If the layer above the overflow is quiescent $\left(v_{\mathrm{A}}=0\right)$, hydraulic control gives the classical value for overflow volume transport, $q=$ $\int v \times h \times \mathrm{d} z=g^{\prime} \times h_{\mathrm{u}}^{2} /(2 \times f)$, which for density difference $\Delta \rho=0.3 \mathrm{~kg} \times \mathrm{m}^{-3}$ and upstream interface height $h_{\mathrm{u}}=$ $300 \mathrm{~m}$ gives $q=1 \mathrm{~Sv}$ (Whitehead, 1998). In this case, the interface will intersect with the bottom at distance $L=\left(2 g^{\prime} \times h_{\mathrm{u}}\right)^{1 / 2} / f \approx 10 \mathrm{~km}$ from the Iceland slope (Whitehead, 1998), which is consistent with the glider sections reported by Beaird et al. (2013). Over the rest of the IFR, the interface will be below or close to sill level, and the overflow weak and intermittent.

Both the rectangular topography and the assumption of zero potential vorticity tend to give too large transport values, but are still remarkably close to observations (Whitehead, 1998). Consistent with this, an overflow of $1 \mathrm{~Sv}$ close to
Iceland seems high, but not far above the estimate of Perkins et al. (1998): "at least $0.7 \mathrm{~Sv}$ ". If, instead of quiescent, the layer above the overflow runs in the opposite direction with a velocity $v_{\mathrm{A}}$ (Fig. 8a), the tilt of the interface $(\mathrm{d} h / \mathrm{d} x$ in Fig. 10a) increases and the overflow becomes narrower and weaker. The model is easily solved numerically, also for this case (Fig. 10b).

The result of such a simple model should be treated cautiously, but it indicates that even a relatively small reduction of $h_{\mathrm{u}}$ may induce a substantial weakening of the IF-overflow and that a strong Atlantic inflow close to Iceland would induce further overflow reduction. This may be by intensification or by a westward shift in the core of the inflow near Iceland. In Sect. 4.1, we generated a continuous time series of the upstream sea-surface height, which explained more than $50 \%$ of the variance in the observed interface height at station $\mathrm{K} 4$ on the K-section. This reconstructed upstream interface height is shown in Fig. 11 together with the observed IFinflow and the simulated Iceland component of the IF-inflow according to the NEMO model. To the extent that we can believe these indicators, IF-overflow through the Western Valley was reduced during the 2003-event both by an exceptionally small upstream interface height and by an exceptionally strong Atlantic inflow above the Western Valley.

It would have been nice to have time series of IF-overflow that might illuminate the discrepancy between observed and simulated IF-inflow for the whole period. From the available material, we have not felt confident to generate such series. Instead, we have focused on what is clearly the largest discrepancy, the 2003-event (Fig. 2a). There, at least, the conclusion seems clear. During this event, the IF-inflow was exceptionally weak, but the IF-overflow was probably also exceptionally weak. Thus, the net flow across the IFR (IFinflow-IF-overflow) may well have been close to average. Since the inflow simulated by the model is in reality the net flow, the discrepancy between observations and model is therefore not as large as indicated in Fig. 2a.

\subsection{Simulated ocean heat transport towards the Arctic}

The warm water carried by the Atlantic inflow is cooled in the Arctic Mediterranean, and most of it returns to the Atlantic with temperatures close to $0{ }^{\circ} \mathrm{C}$, whether by overflow or surface outflow. Heat transport of Atlantic inflow branches is therefore commonly calculated relative to this temperature (Østerhus et al., 2005). By this definition, the average heat transport of the IF-inflow for the 1995-2009 period was estimated (Hansen et al., 2015) to be $124 \mathrm{TW}\left(1 \mathrm{TW}=10^{12} \mathrm{~W}\right)$. The inflow through the FSC was 107 TW (Berx et al., 2013), west of Iceland 24 TW (Jónsson and Valdimarsson 2012), and, through the Bering Strait, about 16 TW (Woodgate et al., 2012). Between the FSC and the European continent there is additional inflow, which is not well constrained by observations, but might account for $0.5 \mathrm{~Sv}$, equivalent to $\sim 25 \mathrm{TW}$, according to vessel-mounted ADCP measurements (Childers 

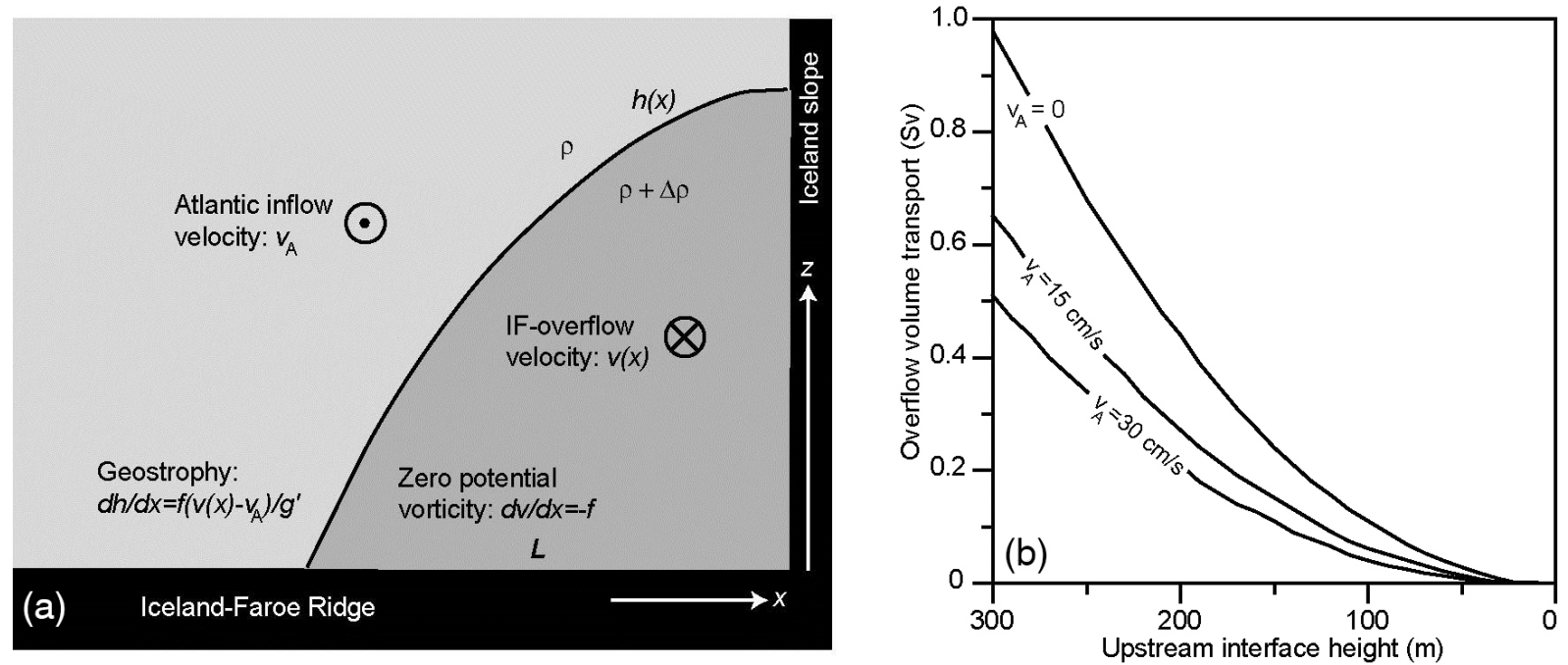

Figure 10. Two-layer model of the Western Valley assuming vertical Iceland slope and zero potential vorticity overflow below an Atlantic inflow of spatially constant velocity $v_{\mathrm{A}}$ (a). Overflow volume transport in the model assuming hydraulic control (maximum transport) as a function of upstream interface height $h_{\mathrm{u}}$ for three different values of Atlantic inflow velocity $v_{\mathrm{A}}(\mathbf{b})$.

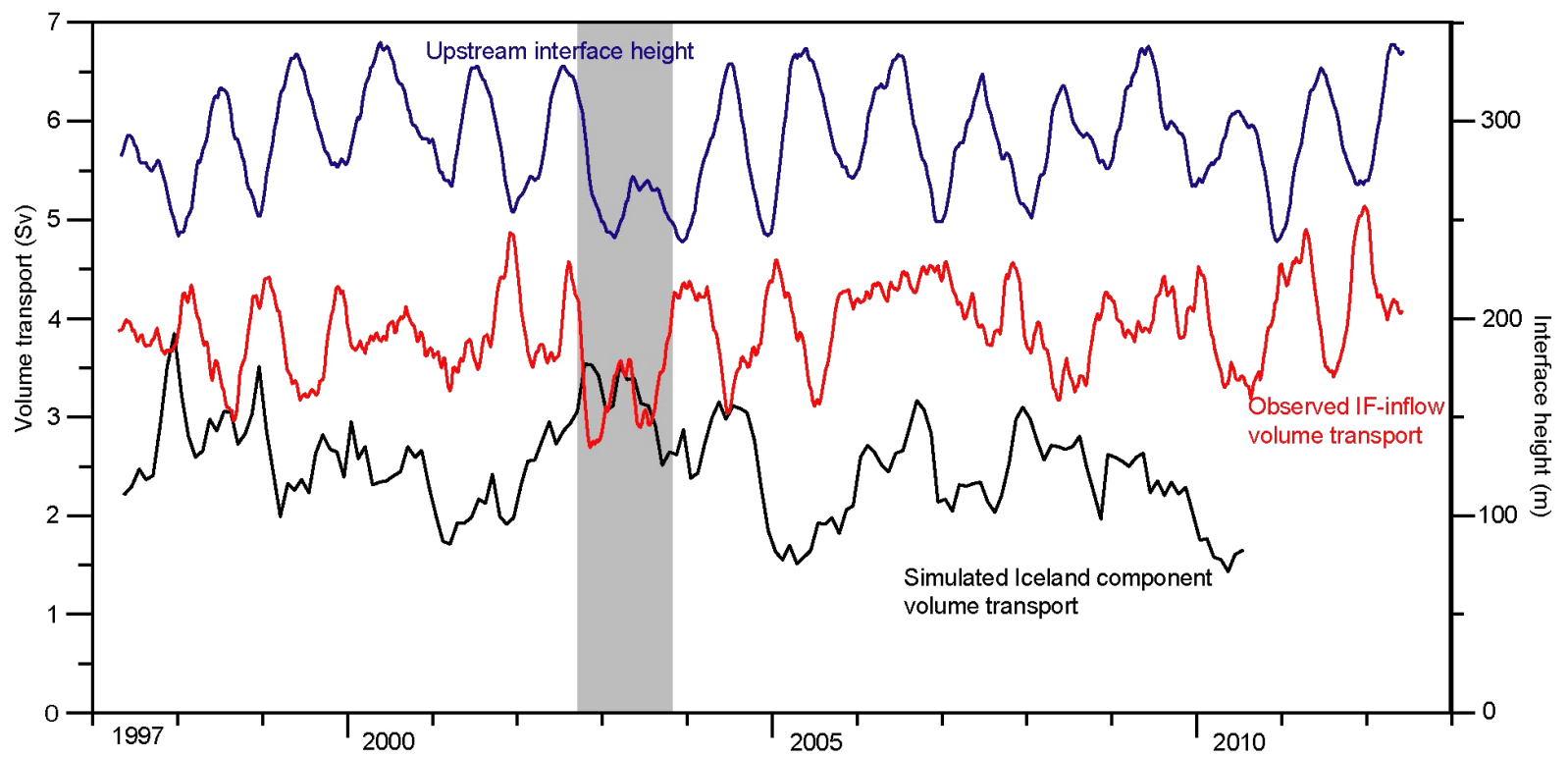

Figure 11. Twelve-week running mean observed IF-inflow (red, left scale) and reconstructed upstream interface height (blue, right scale) and 3-month running mean of the Icelandic component of the simulated IF-inflow (black, left scale). The grey box highlights the 2003-event.

et al., 2014). This brings the total ocean heat transport into the Arctic Mediterranean to approximately $300 \mathrm{TW}$, and the IF-inflow thus accounts for $\sim 40 \%$ of it.

We have demonstrated that the intensity and variability of the IF-inflow is coupled to the overflow and that up to $1 \mathrm{~Sv}$ of the observed IF-inflow is a direct compensation of IFoverflow. The associated heat transport is $\sim 30 \mathrm{TW}$ or about $10 \%$ of the total heat transport. These numbers can be interpreted as the upper limit of the direct mean bias expected in ocean model systems incapable of producing IF-overflow, as only limited compensation is likely to take place in other exchange branches. This is concluded from consistent observations and model results for other inflow branches (Sect. 5), the evidence presented (Sects. 4 and 5) for a dynamic link between inflow and overflow, and the qualitative similarities identified between modelled and true net flow at the IF ridge, both suggesting a reduced level of variability compared to observed inflow as exemplified by the 2003-event. Where the net exchange and IF-inflow clearly did not change signifi- 
cantly in the model, true inflow and outflow may well have weakened by approximately $1 \mathrm{~Sv}$.

From observations, only the IFR exchange system is found to respond strongly to the anomalous conditions during the 2003-event (not shown). However, an intensification of the Atlantic inflow west of Iceland has been observed (Jónsson and Valdimarsson, 2012), though it is moderate compared to the marked decline of the IF inflow. In the model, the baroclinic adjustment of the interface between upper and deep waters north-east of the IFR was confined to an area affecting only the dynamics here (Fig. 5d). Consequently it is unlikely that this sensitivity can be adequately compensated for by changes in other exchange systems across the GSR.

In the model simulation used here, the average IF-inflow is 3.9 Sv for the observational period (Fig. 2) and, thus, almost identical to the observed value (Hansen et al., 2015). But interpreted as the net exchange and assuming that up to $1 \mathrm{~Sv}$ of the observed IF-inflow is on average explained as a direct compensation of IF-overflow, this particular model system has a positive bias of unknown origin but masks, in average terms, the specific limitations discussed here and revealed by studying variations in exchanges.

\subsection{Salt transport, freshwater balance and thermohaline stability}

A further direct consequence of the apparent model collapse of the overturning circulation on the IFR into a unidirectional net flow is essentially a reduced average ventilation rate of the Arctic Mediterranean. Though the properties of the Atlantic inflow are unaffected, a reduced ventilation rate has implications for the freshwater balance. To first order, we can expect the modelled equilibrium salinity difference between inflow and outflow to increase with reduced ventilation rate in order to balance the net precipitation less evaporation and river runoff in the Arctic (e.g. Haine et al., 2014). If we assume that the Atlantic inflow is returned in a diluted form in dense overflows, the required salinity difference is approximately given by $S \times F / V$, where $S$ is a reference salinity (35 psu), $F$ is the freshwater flux and $V$ is the ventilation rate. In the present system, the difference in salinity between inflow and overflow at the GSR ridge is about $0.3 \mathrm{psu}(\varnothing$ sterhus et al., 2005), suggesting the appropriate dilution flux for the vertical overturning loop of the system to be of the order of $0.06 \mathrm{~Sv}$ ( $V=7.5 \mathrm{~Sv}$; see Sect. 5.1). This simplified framework implies that a low biased ventilation rate of $1 \mathrm{~Sv}$ will lead to a further freshening of the overflows by $0.05 \mathrm{psu}$, sufficient to impact on the structure and intensity of the AMOC in the model (Born et al., 2009; Danabasoglu et al., 2010; Köller et al., 2010; Wang et al., 2015). Also, the stability of the AMOC in the climate models of varying complexity is likely related to the intensity of the vertical overturning (e.g. Boulton et al., 2014), and resolving these deficiencies may result in ocean model systems less sensitive to enhanced high-latitude freshening (Swingedouw et al., 2015).
The suggested relationship between IF-inflow and IFoverflow during the 2003-event has potentially only modest implications for the variability in the salt transport. At any given time, the net salt import to the Nordic Seas across the IFR is $q_{\mathrm{i}} \times S_{\mathrm{i}}-q_{\mathrm{o}} \times S_{\mathrm{o}}$, where $q_{\mathrm{i}}, S_{\mathrm{i}}, q_{\mathrm{o}}$ and $S_{\mathrm{o}}$ are volume transports and salinities of the IF-inflow and IF-overflow, respectively. During the 2003-event, there was a reduction, $\Delta q$, of the inflow transport, and hence a reduction in salt transport equal to $\Delta q \times S_{\mathrm{i}}$ in the IF-inflow. According to our results, this was compensated for by a similar reduction in IF-overflow, and the net import of salt was only reduced by approximately $\Delta q \times\left(S_{\mathrm{i}}-S_{\mathrm{O}}\right)$, which is much smaller, since $S_{\mathrm{o}} \approx 34.9 \approx 0.99 \times S_{\mathrm{i}}$.

The evidence for a strongly reduced IF-overflow during the 2003-event thus implies that there was in nature a relatively stable net import of salt in qualitative agreement with the model simulations. Despite this apparently very fortunate cancellation of model errors, it masks the fact that during the 2003-event the model supply of near-surface highsalinity Atlantic water to the convective areas of the Nordic Seas was biased high by $\Delta q \times S_{\mathrm{i}}$. This will have implications for the preconditioning of convection and feedback on simulated exchanges since Glessmer et al. (2014) have shown that the salinity variations in the Nordic Seas are predominantly caused by variations in the Atlantic inflow. It seems likely that this will also impact the stability of the model thermohaline exchanges, but lack of a quantitative time series of IF-overflow makes it difficult to assess this observationally.

\section{Conclusion and perspectives}

Combining model results with observations, this paper has addressed a topic challenging for CMIP5-type coarseresolution large-scale ocean general circulation models: the simulation of ocean exchanges across a shallow submarine ridge.

With offset in the observational data describing the conditions on and exchanges across the IFR, central model limitations have been identified. Contrary to observations, simulated transport across the IFR consists solely of Atlantic inflow and is by definition also the net transport in the model system. It was shown to be plausible that variations in modelled volume transport may compare at least qualitatively with variations in the real net volume transport - the residual of Atlantic inflow and dense, cold overflow of intermediate water from the Nordic Seas. Hereby we offer an explanation for the striking discrepancy between model results and observed variations in the strength of the Atlantic inflow, which serves to verify the monitoring system and some characteristics of the model physics including the sensitivity of the net flow to variations in atmospheric forcing. It is shown that coarse, global ocean model systems operate in a regime where important feedbacks in the exchange system on the IFR are not invoked, limiting the variability of this central 
branch. To make this interpretation plausible, other aspects of the model response in the IFR region indirectly linked to the exchanges on the ridge have been verified. Other climate model limitations that directly or indirectly affect the ventilation rates have not been addressed.

The representation of only the net exchange does, however, affect how heat and salt transport towards the Arctic is simulated. Even assuming the net flow is realistic, model systems will simulate a low biased transport of heat. Though this bias is arguably low compared with the poleward heat transport in the atmosphere, it is not obvious that compensation here can account correctly for inadequate ocean heat transport in the climate system. In ocean regions bordering the Arctic, temperature controls conditions for sea-ice formation, and oceanic heat is made directly available for seaice melt. Through these mechanisms, ocean heat transport is believed to play a disproportionally strong role in the climate system (Rhines et al., 2008), and correct simulation is essential for realistic climate sensitivity in climate models. The results presented serve to underline the present uncertainty in climate projections by identifying and quantifying model limitations and quantifying their effect on heat transport. For the salt transport, correct simulation may potentially be even more critical due to the feedback on ventilation and overturning strength (Stommel, 1961; Latif et al., 2000). For the extreme 2003-event, we find that the simulated stability of the salt transport was in fact realistic due to the link between IF-inflow and IF-overflow, but more general conclusions are hampered by our lack of observational evidence on IF-overflow intensity and variation.

In order to improve reliability in climate projections, climate models need to be developed to account for the IFoverflow as a driver of part of the warm inflow. It is unclear whether efforts to date have in fact achieved this in coarseresolution systems (e.g. Wang et al., 2015), and it seems unlikely that improvements in resolution in the next generation of climate projections will alone resolve this considering the need to resolve the meso-scale flows with length scales of the order of $10 \mathrm{~km}$ (Whitehead, 1998).

Climate model systems are used intensively in seasonal to decadal prediction systems where part of the skill in the Northern Hemisphere and Arctic region is related to ocean heat anomalies (Latif and Keenlyside, 2011; Meehl et al., 2014; Guemas et al., 2014). Our results demonstrate a reduced level of variability compared to observations in the branch of the Atlantic inflow to the Arctic associated with the largest average heat transport. This suggests that predictability for the region may at present be strongly limited by this model deficit alone. From an atmospheric perspective, it has been established that the level of variability is positively linked to predictive capabilities (e.g. Sun and Wang, 2013).

Efforts should also be made to provide more representative observational constraints on the IF-overflow, especially close to Iceland.
Acknowledgements. The research leading to these results has received funding from NACLIM, a project of the European Union 7th Framework Programme (FP7 2007-2013) under grant agreement no. 308299. S. M. Olsen and B. Hansen were partly funded by the Danish Strategic Research programme through the NAACOS project.

Edited by: A. Sterl

\section{References}

Årthun, M., Eldevik, T., Smedsrud, L. H., Skagseth, Ø., and Ingvaldsen, R. B.: Quantifying the Influence of Atlantic Heat on Barents Sea Ice Variability and Retreat, J. Clim., 4736-4743, doi:10.1175/JCLI-D-11-00466.1, 2012.

Beaird, N. L., Rhines, P. B., and Eriksen, C. C.: Overflow Waters at the Iceland-Faroe Ridge Observed in Multiyear Seaglider Surveys, J. Phys. Oceanogr., 43, 2334-2351, 2013.

Berx, B., Hansen, B., Østerhus, S., Larsen, K. M., Sherwin, T., and Jochumsen, K.: Combining in situ measurements and altimetry to estimate volume, heat and salt transport variability through the Faroe-Shetland Channel, Ocean Sci., 9, 639-654, 2013.

Bitz, C. M., Holland, M. M., Weaver, A. J., and Eby, M.: Simulating the ice-thickness distribution in a coupled climate model, J. Geophys. Res., 106, 2441-2463, 2001.

Born, A., Levermann, A., and Mignot, J.: Sensitivity of the Atlantic ocean circulation to a hydraulic overflow parameterisation in a coarse resolution model: response of the subpolar gyre, Ocean Model., 27, 130-142, 2009.

Boulton, C. A., Allison, L. C., and Lenton, T. M.: Early warning signals of Atlantic Meridional Overturning Circulation collapse in a fully coupled climate model, Nat. Commun., 5, 5752, doi:10.1038/ncomms6752, 2014.

Childers, K. H., Flagg, C. N., and Rossby, T.: Direct velocity observations of volume flux between Iceland and the Shetland Islands, J. Geophys. Res. Oceans, 119, 5934-5944, 2014.

Danabasoglu, G., Large, W. G., and Briegleb, B. P.: Climate impacts of parameterized Nordic Sea overflows, J. Geophys. Res., 115, C11005, doi:10.1029/2010JC006243, 2010.

Dickson, R. R., and Brown, J.: The production of North Atlantic Deep Water: Sources, rates, and pathways, J. Geophys. Res., 99, 12319-12341, 1994.

Glessmer, M. S., Eldevik, T., Våge, K., Nilsen, J. E. Ø., and Behrens, E.: Atlantic origin of observed and modelled freshwater anomalies in the Nordic Seas, Nature Geosci., 7, 801-805, 2014.

Guemas, V., Blanchard-Wrigglesworth, E., Chevallier, M., Day, J. J., Déqué, M., Doblas-Reyes, F. J., Fučkar, N. S., Germe, A., Hawkins, E., Keeley, S., Koenigk, T., Salas y Mélia, D., and Tietsche, S.: A review on Arctic sea ice predictability and prediction on seasonal-to-decadal timescales, Q. J. R. Meteorol. Soc., 142, 546-561, doi:10.1002/qj.2401, 2014.

Guo, C., Ilicak, M., Fer, I., Darelius, E., and Bentsen, M.: Baroclinic Instability of the Faroe Bank Channel Overflow, J. Phys. Oceanogr., 44, 2698-2717, 2014.

Hansen, B. and Østerhus, S.: North Atlantic-Nordic Seas exchanges, Prog. Oceanogr., 45, 109-208, 2000.

Hansen, B. and Østerhus, S.: Faroe bank channel overflow 19952005, Prog. Oceanogr., 75, 817-856, 2007. 
Hansen, B., Østerhus, S., Hátún, H., Kristiansen, R., and Larsen, K. M. H.: The Iceland-Faroe inflow of Atlantic water to the Nordic seas, Prog. Oceanogr., 59, 443-474, 2003.

Hansen, B., Hátún, H., Kristiansen, R., Olsen, S. M., and Østerhus, S.: Stability and forcing of the Iceland-Faroe inflow of water, heat, and salt to the Arctic, Ocean Sci., 6, 1013-1026, doi:10.5194/os-6-1013-2010, 2010.

Hansen, B., Larsen, K. M. H., Hátún, H., Kristiansen, R., Mortensen, E., and Østerhus, S.: Transport of volume, heat, and salt towards the Arctic in the FaroeCurrent 1993-2013, Ocean Sci., 11, 743-757, doi:10.5194/os-11-743-2015, 2015.

Haine, T. W., Curry, B., Gerdes, R., Hansen, E., Karcher, M., Lee, C., Rudels, B., Spreen, G., de Steur, L., Stewart, K. D., and Woodgate, R.: Arctic freshwater export: Status, mechanisms, and prospects, Glob. Plane. Change, 125, 13-35, 2015.

Hazeleger, W., Wang, X., Severijns, C., Ştefănescu, S., Bintanja, R., Sterl, A., Wyser, K., Semmler, T., Yang, S., van den Hurk, B., van Noije, T., van der Linden, E., and van der Wiel, K.: EC-Earth V2. 2: description and validation of a new seamless earth system prediction model, Clim. Dynam., 39, 2611-2629, 2012.

Hermann, F.: The T-S diagram analysis of the water masses over the Iceland-Faroe ridge and in the Faroe Bank Channel, in: Rapp. PV Réun. Cons. Perm. Inter. Exp/or. Mer, 157, 139-149, 1967.

Hurrell, J. W.: Influence of variations in extratropical wintertime teleconnections on Northern Hemisphere temperature, Geophys. Res. Let., 23, 665-668, 1996.

Jónsson, S. and Valdimarsson, H.: Water mass transport variability to the North Icelandic shelf, 1994-2010, ICES J. Mar. Sci., 69, 809-815, 2012.

Kalnay, E., Kanamitsu, M., Kistler, R., Collins, W., Deaven, D., Gandin, L., Iredell, M., Saha, S., White, G., Woollen, J., Zhu, Y., Leetmaa, A., Reynolds, R., Chelliah, M., Ebisuzaki, W., Higgins, W., Janowiak, J., Mo, K. C., Ropelewski, C., Wang, J., Jenne, R., and Joseph, D.: The NCEP/NCAR 40-Year Reanalysis Project, Bull. Amer. Meteor. Soc., 77, 437-471, 1996.

Koenigk, T. and Brodeau, L.: Ocean heat transport into the Arctic in the twentieth and twenty-first century in EC-Earth, Clim. Dynam., 42, 3101-3120, 2014.

Köller, M., Käse, R. H., and Herrmann, P.: Interannual to multidecadal variability and predictability of North Atlantic circulation in a coupled earth system model with parametrized hydraulics, Tellus A, 62, 569-578, 2010.

Lake, I. and Lundberg, P.: Seasonal barotropic modulation of the deep-water overflow through the Faroe Bank Channel, J. Phys. Oceanogr, 36, 2328-2339, 2006.

Latif, M. and Keenlyside, N. S.: A perspective on decadal climate variability and predictability, Deep-Sea Res. Pt. II, 58, 18801894, 2011.

Latif, M., Roeckner, E., Mikolajewicz, U., and Voss, R.: Tropical stabilization of the thermohaline circulation in a greenhouse warming simulation, J. Climate, 13, 1809-1813, 2000.

Meincke, J.: The modern current regime across the GreenlandScotland Ridge, in Structure and development of the GreenlandScotland Ridge, edited by: Bott, M., Saxov, S., Talwani, M., and Theide, J., Springer, New York, 637-650, 1983.

Meehl, G. A., Goddard, L., Boer, G,. Burgman, R., Branstator, G., Cassou, C., Corti, S., Danabasoglu, G., Doblas-Reyes, F., Hawkins, E., Karspeck, A., Kimoto, M., Kumar, A., Matei, D., Mignot, J., Msadek, R., Pohlmann, H., Rienecker, M., Rosati, T.,
Schneider, E., Smith, D., Sutton, R., Teng, H., van Oldenborgh, G. J., Vecchi, G., and Yeager, S.: Decadal climate prediction: an update from the trenches, Bull. Am. Meteorol. Soc., 95, 243267, 2014.

Olsen, S. M. and Schmith, T.: North Atlantic-Arctic Mediterranean exchanges in an ensemble hindcast experiment, J. Geophys. Res., 112, C04010, doi:10.1029/2006JC003838, 2007.

Olsen, S. M., Hansen, B., Quadfasel, D., and Østerhus, S.: Observed and modelled stability of overflow across the GreenlandScotland ridge, Nature, 455, 519-522, 2008.

Østerhus, S., Turrrell, W. R., Jónsson, S., and Hansen, B.: Measured volume, heat, and salt fluxes from the Atlantic to the Arctic Mediterranean, Geophys. Res. Lett., 32, L07603, doi:10.1029/2004GL022188, 2005.

Perkins, H., Hopkins, T. S., Malmberg, S. A., Poulain, P. M., and Warn-Varnas, A.: Oceanographic conditions east of Iceland, J. Geophys. Res. Oc., 103, 21531-21542, 1998.

Rahmstorf, S. and Ganopolski, A.: Long-term global warming scenarios computed with an efficient coupled climate model, Clim. Change, 43, 353-367, doi:10.1023/A:1005474526406, 1999.

Rhines, P., Häkkinen, S., and Josey, S. A.: Is the oceanic heat transport significant in the climate system?, in: Arctic-Subarctic Ocean Fluxes: Defining the Role of the Northern Seas in Climate, edited by: Dickson, R. R., Meincke, J., and Rhines, P., Springer, Dordrecht, Netherlands, 87-110, 2008.

Richter, K., Segtnan, O. H., and Furevik, T.: Variability of the Atlantic inflow to the Nordic Seas and its causes inferred from observations of sea surface height, J. Geophys. Res., 117, C04004, doi:10.1029/2011JC007719, 2012.

Sandø, A. B., Nilsen, J. E., Eldevik, T., and Bentsen, M.: Mechanisms for variable North Atlantic-Nordic seas exchanges, J. Geophys. Res., 117, C12006, doi:10.1029/2012JC008177, 2012.

Sterl, A., Bintanja, R., Brodeau, L., Gleeson, E., Koenigk, T., Schmith, T., Semmler, T., Severijns, C., Wyser, K., and Yang, S.: A look at the ocean in the EC-Earth climate model, Clim. Dynam., 39, 2631-2657, 2012.

Stommel, H.: Thermohaline Convection with Two Stable Regimes of Flow, Tellus XIII, 2, 224-230, 1961.

Sun, B. and Wang, H.: Larger variability, better predictability?, Int J. Climatol., 33, 2341-2351, 2013.

Sutton, R. T. and Hodson, D. L.: Atlantic Ocean forcing of North American and European summer climate, Science, 309, 115118,2005

Swaters, G. E.: On the baroclinic instability of cold-core coupled density fronts on a sloping continental shelf, J. Fluid Mech., 224, 361-382, 1991.

Swingedouw, D., Rodehacke, C. B., Olsen, S. M., Menary, M., Gao, Y., Mikolajewicz, U., and Mignot, J.: On the reduced sensitivity of the Atlantic overturning to Greenland ice sheet melting in projections: a multi-model assessment, Clim. Dynam., 44, 32613279, doi:10.1007/s00382-014-2270-x, 2015.

Taylor, K. E., Stouffer, R. J., and Meehl, G. A.: An overview of CMIP5 and the experiment design, Bull. Amer. Meteor. Soc., 93, 485-498, 2012.

Vellinga, M. and Wood, R. A.: Global climatic impacts of a collapse of the Atlantic thermohaline circulation, Clim. Change, 54, 251267, 2002.

Vihma, T.: Effects of Arctic Sea Ice Decline on Weather and Climate: A Review, Surv. Geophys., 35, 1175-1214, 2014. 
Voet, G. and Quadfasel, D.: Entrainment in the Denmark Strait overflow plume by meso-scale eddies, Ocean Sci., 6, 301-310, doi:10.5194/os-6-301-2010, 2010.

Wang, H., Legg, S. A., and Hallberg, R. W.: Representations of the Nordic Seas Overflows and Their Large Scale Climate Impact in Coupled Models, Ocean Model., 86, 76-92, 2015.

Whitehead, J. A.: Topographic control of oceanic flows in deep passages and straits, Rev. Geophys., 36, 423-440, 1998.
Woodgate, R. A., Weingartner, T. J., and Lindsay, R.: Observed increases in Bering Strait oceanic fluxes from the Pacific to the Arctic from 2001 to 2011 and their impacts on the Arctic Ocean water column, Geophys. Res. Lett., 39, L24603, doi:10.1029/2012GL054092, 2012.

Yang, S. and Christensen, J. H.: Arctic sea ice reduction and European cold winters in CMIP5 climate change experiments, Geophys. Res. Lett., 39, L20707, doi:10.1029/2012GL053338, 2012.

Yashayaev, I. and Seidov, D.: The role of the Atlantic Water in multidecadal ocean variability in the Nordic and Barents Seas, Prog. Oceanogr., 132, 68-127, 2015. 